\section{DE DE GRUYTER} OPEN
Journal of Intercultural Management Vol. 5, No. 2, June 2013, pp. 63-71 DOI 10.2478/joim-2013-0010

Ernesto León Castro

Universidad de Occidente

Marcela Rebeca Contreras Loera

Universidad de Occidente

\title{
Decision making in the financial management of the business enterprise
}

\begin{abstract}
The globalization within markets has required continuous decision making by employers, so that processes and ways to implement them have become more complex, requiring more quality information on the operations of the company enabling them to make the right decisions.
\end{abstract}

Keywords: decision making, financial managment, business enterprise.

\section{Introduction}

The impact of the decisions in different areas of the company management is significant, since a wrong decision in one area has a ripple effect with the other, so it should be taken into account when deciding how are you going to affect the entire company and not just the department where taken.

One of the difficulties faced by small and medium-sized enterprises (SMEs) according to De la Torre (2006) is that most of the responsibilities within the company are not covered by several people, but it is the same owner who must face and solve most problems that arise, which is why the decision of the company is heavily influenced by the personality, preferences and behavior of the entrepreneur, leading to have a very limited management.

It is for this that in the present investigation was aimed at identifying the main decision-making process in the financial management of the business enterprise, using a qualitative methodology occurred because descriptive data came from key informants and observable behaviors within the organization thus lived more closely the phenomenon under investigation. 


\section{Materials and Methods}

The methodology used in this study is the qualitative research refers in its broadest sense to research that produces descriptive data: the words of the people, spoken or written and observable behavior, resulting in a report of a more closely the phenomenon as it is lived in small and medium enterprises [Taylor, 1987].

\section{The data collection instruments were used in this are:}

Interviews were used primarily to three people who are involved in decision making are: the owner, the manager of sale and inventory manager, which was held for an interview guide for each of these.

Other data collection instrument used was the observation; this was the way of daily operation within the organization in order to determine how the company works.

Finally we used the analysis of internal company documents, this is sought to determine the way it should be in the works within the company and compare it with the information obtained in the interviews and observation.

\section{Decision Making}

Due to the competitive environment we are living in today's world, markets are changing at a rapid pace, companies until recently were immune to globalization, but now that most markets are open and communication ceased to be a constraint, currently enterprises not only compete with local companies but also with all companies in the world [Contreras, 2007].

Decision making can be defined in different ways, while Koontz [2004] defines it as the selection of a course of action among several alternatives, other authors such as Daft [2007] states that organizational decision making is formally defined as the process of identifying and solving problems, taking into account Chiavenato [2006] indicates that it is the process of analyzing and choosing among alternative courses of action available to the person should continue, adding that any decision involves six elements: taking decisions, goals, preferences, strategy, location, result.

The decision process involves following a series of steps by which is defined what will be done in order to make better decisions. These processes gives us the ease of troubleshooting or face different situations, is complex and depends on the personal characteristics of the person who is making the decision, the situation that we are experiencing and how they perceive the situation. The steps for this process are different according to the author we read, each researcher submits a proposal according to the results of studies where the steps can be from two to eight (see Table 1). 
Table 1. Decision making process

\begin{tabular}{|c|c|c|c|}
\hline Chiavenato (2006) & Robbins (2005) & Daft (2000) & Drucker (2006) \\
\hline $\begin{array}{l}\text { 1. Perception of a } \\
\text { problem }\end{array}$ & 1. Identify a problem & $\begin{array}{l}\text { 1. Problem } \\
\text { identification }\end{array}$ & $\begin{array}{l}\text { 1. Classification of the } \\
\text { problem }\end{array}$ \\
\hline $\begin{array}{l}\text { 2. Analysis and } \\
\text { definition of the } \\
\text { problem }\end{array}$ & $\begin{array}{l}\text { 2. Identify the } \\
\text { decision criteria }\end{array}$ & 2. Solution & 2. Defining the problem \\
\hline 3. Defining goals & $\begin{array}{l}\text { 3. Assign weights to } \\
\text { criteria }\end{array}$ & & $\begin{array}{l}\text { 3. Conditions that must } \\
\text { satisfy the answer to } \\
\text { the problem }\end{array}$ \\
\hline $\begin{array}{l}\text { 4. Search for } \\
\text { alternative solutions } \\
\text { or courses of action }\end{array}$ & $\begin{array}{l}\text { 4. Develop } \\
\text { alternatives }\end{array}$ & & $\begin{array}{l}\text { 4. Decide on what is } \\
\text { right, rather than on } \\
\text { what is acceptable, } \\
\text { in order to meet field } \\
\text { conditions }\end{array}$ \\
\hline $\begin{array}{l}\text { 5. Select the most } \\
\text { appropriate decision } \\
\text { to achieve the } \\
\text { objectives }\end{array}$ & $\begin{array}{l}\text { 5. Analyze } \\
\text { alternatives }\end{array}$ & & $\begin{array}{l}\text { 5. Include in the } \\
\text { decision actions to be } \\
\text { carried out }\end{array}$ \\
\hline $\begin{array}{l}\text { 6. Evaluation and } \\
\text { comparison of } \\
\text { alternatives }\end{array}$ & $\begin{array}{l}\text { 6. Select an } \\
\text { alternative }\end{array}$ & & $\begin{array}{l}\text { 6. Set the control to } \\
\text { check the validity and } \\
\text { effectiveness of the } \\
\text { decision in relation to } \\
\text { the current state of the } \\
\text { facts }\end{array}$ \\
\hline \multirow[t]{2}{*}{$\begin{array}{l}\text { 7. Implementation } \\
\text { of the selected } \\
\text { alternative }\end{array}$} & $\begin{array}{l}\text { 7. Implement } \\
\text { alternative }\end{array}$ & & \\
\hline & $\begin{array}{l}\text { 8. Evaluate the } \\
\text { efficacy of the } \\
\text { decision }\end{array}$ & & \\
\hline
\end{tabular}

Source: Own elaboration, with data of different authors.

One of the most important points to be identified is that the decisions made within organizations range in complexity, since in practice there is a myriad of problems or situations that require you to make a decision. This is why it is necessary to classify the decisions made, as there are programmed decisions are those that are repetitive and planned by the company, so the decision is given to this is usually the same in most cases, however, there are other decisions 
that are not scheduled, these are those that are unforeseen problems and are generally unknown to the company, so this is where you make the best decision seeks to address that problem the best way.

\section{Financial management}

Financial management studies management decisions that lead to the acquisition and financing of fixed and current assets of the company. As handles such situations requiring an appropriate selection assets or make a suitable selection debts [Philippatos, 1979].

The objectives of financial management should be in line with those of the organization, however Villareal [2001] considers that the objectives to be achieved by a company are:

- Survival and growth of business

- Getting utilities

- Image and prestige

- Social acceptance

Cash management

The cash of the company allows you to buy new goods or liquidating its commitments, with the result that there are sometimes cash surpluses or shortages. Both are inadequate for the company financially, because excess cash creates a leisure and missing affects the obligations paying premiums, interest or late payment because not had the need to settle the transaction resource [Stevenson, 2003].

Efficient cash management must be based on the objective and policies established by the company and Morelos [2005] tells us that you have to avoid is:

- Unnecessary costs. Is achieved by running a tight internal control over expenditures to make

- Reduction incidentals. However they are concepts that cannot be avoided, it is possible to purchase insurance policies, maintenance contracts, among other ways to decrease spending any problems generated unscheduled

- Investments. You need a budget consist of investments, which are investments in programs to major and date of completion, not to distort the cash flow information

- Use discount. It is advisable to anticipate the payment of the obligations or which would cause interest gain, only when surplus cash count, situation that leverages the opportunity cost

- Temporary investments. Their goal is to invest excess cash for performance without limiting the liquidity of the company, which is recommended to invest in fixed income securities and short-term. 
Inventory management

The inventory consists of those tangible assets owned by a company that has to sell and / or used for the production of goods and services.

Inventory usually listed as a short-term asset for the company, as it is considered to be converted into cash within a period of less than a year, so it is in the current assets in the balance sheet [Starr, 2004 ].

When a company decides to take inventory this has different costs Galindo [1998] comments that are:

- Cost of capital invested. The most important of all, because the money invested in inventory is no longer available for use in different activities. Therefore, determine an opportunity cost equal to the gain that could be obtained by using the money in investments in securities and similar risks.

- Cost of storage. This cost varies depending mainly on whether the cellar is owned or leased by the company. In the first case to be included in the tax expense and depreciation.

- Cost per service. This is when you make extra payments for special services for the care and maintenance of inventory such as insurance, purchase of equipment for the care of inventory, etc.

- Costs associated with risk. This is a cost that is often not clearly seen by employers, because the risk is that the inventory is lost, damaged, expired or obsolete.

\section{Accounts receivable management}

Accounts receivable represent enforceable rights arising from sales, services, loans granted by or any other similar concept. Can form two groups of accounts receivable: customers and other debtors. Within the first must submit the documents and accounts by customers of the bank, from the sale of merchandise. In the second are caused by transaction accounts other than those for which it was constituted entity such as loans to shareholders, officers and employees [Financial Reporting Standards, 2007].

The accounts receivable management is important because it is a tool that companies use to keep their regular customers and attract new ones. Usually the credit relates to credibility and trust. A healthy credit management according to Sanchez [2004] should lead to the achievement of:

- Analyze the credit risk. Try to determine who will receive the credit and under what conditions

- Set standards for acceptance of credit. Represents the feature specifications that determine the approval or denial of credit

- Set reasonable credit terms. These define the period over which extends the credit 
- Determine how the risk can be absorbed. Once the decision is made there is a risk that the account cannot be recovered

- Determine how to be financed asset increases. There are several funding mechanisms and policies according to domestic debt of each company, or define the mechanisms to select.

- Establish a reasonable billing policy. Good credit can become a bad credit if not given proper monitoring. The collection policy should establish mechanisms to prevent this from happening.

Profitability

Although most companies make profit as an indicator of the efficiency of the economic activity of the company, however this is not enough, especially for the purposes of comparison, since the absolute magnitude, which depends essentially of the output characteristics. This is why it is convenient to relate the gain with other factors of production, the effect of having a state. This is known as profitability [Pichardo, 1995].

The return is the result of the relationship between a variable found in the income statement, which is useful, and a balance sheet item, which is capital [Jaramillo, 2008].

Performance is calculated as the ratio between profit and invested capital for the utility, so the formula used to calculate it would be:

Performance $=$ Profit $/$ Capital Employed

The strategic objectives that the company regarding its profitability targets according to Koenes [1995] are:

- Exploitation. The company targets a priority to reach the highest levels of benefits in the shortest time possible. The ultimate purpose of this is to achieve the highest possible gain in the shortest time.

- Stability. The company aims to achieve a stable generation of benefits for an extended period of time. Its purpose is to maintain a balance between revenue, expenses and benefits that allow while generating an acceptable return, all in order to consolidate the company, product or service.

- Investment. The company chooses to invest as much as possible in their own development or of all or any of the products or services they sell. The ultimate purpose is to buy market share waiting to achieve in the future higher profit levels.

\section{Results}

In a matter of decision makers within the company, according to research found that people are as follows:

- The owner. - This person is responsible for giving the nods to all decisions are to be taken within the company, as it relates to decisions unscheduled. 
- Manager of sale. - This person makes decisions related to the purchase of products within the company, as well as being in charge of deciding how the credits will be awarded to customers

- Inventory Manager. - This person is the one who decides how the goods will be distributed within the company, the amount needed and where to find them if the store or warehouse.

While the administrators according to their hierarchy have the knowledge and ability to make decisions within the company, in reality this does not happen, because any decision about the direction of the company, even if they have performed the analysis respective decision and find a suitable for the problem, in the end will be the owner to decide the course of action, leaving disabled administrator's decision, and only about respecting the figure of the owner.

Regarding the decision making process within the company found that the following steps are:

- Identification of the problem. - It's that point where managers or owner detect the need for intervention.

- Analysis of the problem. - Once identified is required for analysis to determine the magnitude of the problem and find the necessary information to serve as a basis for solving it.

- Define the objectives. - Must seem to be achieved with the solution of the problem, which is why after analysis is necessary to identify where you want to go to have a clear and specific view.

- Identify the different alternatives. - The same problem has different solutions, so before selecting a must detect all possible paths.

- Evaluate the alternatives. - At this point the company analyzes all possible solutions in order to find the ideal according to the objectives to be achieved.

- Implementation of the alternative. - Here is where the administrator or owner which will decide the way forward for the company and put that into action alternative.

As can be seen according to the steps that are used within the company, these are related to those mentioned Chiavenato [2005], however even though this mentions seven steps, the company uses six steps presented by the author.

With respective to cash management within the company the person responsible for making decisions in this area is only the owner, who does not have a cash flow in the form, so it cannot reach the benefits that Morelos [2005] tell us, as there are moments in which the company has surplus cash and others in which there are shortages within the bank accounts. 
In a matter of inventories there are two individuals responsible for the decision-making that are the manager of inventory and the owner. The problem detected is that within the various costs of store that Galindo [1998] mentioned, the company has detected none, but its main concern is to have the product when the client needs no matter the cost that this brings with it.

With respective to account receivable were detected two people who are responsible for decision-making that are the manager of sale and the owner, here are normally detected the recommendations made by Sanchez [2004] for a healthy credit administration, however customers that are related to the owner don't follow the rules, this because their credit exceed established credit days in textbooks and is the owner who decides the terms of such loans without consulting any manual or the manager of sale.

In the case of profitability was found that the owner is the person who is responsible for making this decision, however this is not very aware of how it is going to be reach, that is why he doesn't follow one strategy, but adapts to the needs of the company, and even though Koenes [1995] presents us strategy depending on the goal of profitability in this case the company does not use them.

\section{Conclusion}

In Mexico more than $99 \%$ of the companies are small and medium which largely contribute to job creation, but the survival of these companies in the market is very limited, studies show that 100 companies that are born $30 \%$ die in the first year and between $60 \%$ and $70 \%$ over the next 5 years, this reflects the instability of the same. That is why we recognize the importance that SMEs make good choices that enable them to stay in the market and take advantage of opportunities that arise within it.

In this work we identify the process of decision making in the financial management of the business enterprise, in order to find points of improvements in the process so they can help businesses stay more time in the market, as observed the lifetime of these in the market is very limited and it is necessary to enable them to make better decisions that help them to stay more time in the market and have a healthy administration.

\section{Bibliography}

Chiavenato, A. (2006). Introduction to the general theory of management. Mexico: Mc Graw Hill.

Contreras, L. M. (2007). The transformation from small to large companies. The case of the Sinaloa organization. Mexico: Universidad Autonoma Metropolitana.

Daft, R. (2007). Theory and organizational design. Mexico: Thompson Publishing.

De la Torre, H. C. (2006). Human resource management in SMEs: Contrurama Pacific 
Pipes and Fittings. Puebla: Universidad de las Americas Puebla.

Drucker, P. (2006). Decision making. USA: Harvard Business Review.

Galindo, J. (1998). Inventory management and its application in a company of perfumes and cosmetics. Guatemala: Universidad Francisco Marroquin.

Jaramillo, J. (2008). Proposal for a Model of Financial Performance for exporting SMEs in Monterrey, Nuevo Leon, Mexico. Mexico: Universidad Autonoma de Tamaulipas.

Koenes, A. (1995). Objective: Profitability. Madrid: Ediciones Diaz de Santos.

Koontz, H. and. (2004). Administration. A global perspective. Mexico: Mc Graw-Hill.

Morelos, C. J. (2005). Finance II the company's treasury. Mexico: Universidad Autonoma de Mexico.

Philippatos, G. (1979). Fundamentals of Financial Management. Mexico: Mc Graw Hill.

Pichardo, P. (1995). Industrial Business Economics. Havana: Pueblo and editing.

Robbins, S. (2005). Administration. Mexico: Pearson Education.

Sanchez, I. (2004). Asset management in the short term. Venezuela: Carabobo University.

Starr, M. (2004). Inventory Control. Mexico: Diana.

Stevenson, R. (2003). Findamentos Finance. Mexico: Mc Graw Hill.

Taylor, B. (1987). Introduction to qualitative research methods. New York: Basic Paidos.

Villareal, N. (2001). Financial Management of Assets of a small business. Mexico: Universidad Autonoma de Nuevo Leon. 